\title{
Influence of Psychosocial Factors and Habitual Behavior in Temporoman- dibular Disorder-Related Symptoms in a Working Population in Japan
}

\author{
Akira Nishiyama ${ }^{1,{ }^{*}}$, Koji Kino $^{1}$, Masashi Sugisaki ${ }^{2}$ and Kaori Tsukagoshi ${ }^{1}$ \\ ${ }^{1}$ Temporomandibular Joint and Oral Function, Comprehensive Oral Health Care, Comprehensive Patient Care, Gradu- \\ ate School, Tokyo Medical and Dental University, Tokyo, Japan \\ ${ }^{2}$ Department of Dentistry, Jikei University School of Medicine, Tokyo, Japan
}

\begin{abstract}
Background: The symptoms of temporomandibular disorders (TMD) are directly influenced by numerous factors, and it is thought that additional factors exert indirect influences. However, the relationships between TMD-related symptoms (TRS) and these contributing factors are largely unknown. Thus, the goal of the present study was to investigate influences on TRS in a working population by determining the prevalence of TRS, analyzing contributing factors, and determining their relative influences on TRS.

Materials and Methods: The study subjects were 2203 adults who worked for a single company. Subjects completed a questionnaire assessing TRS, psychosocial factors (stress, anxiety, depressed mood, and chronic fatigue), tooth-contacting habit, and sleep bruxism-related morning symptoms, using a 5-point numeric rating scale. Our analysis proceeded in 2 phases. First, all variables of the descriptor were divided into parts by using an exploratory factor analysis. Second, this factorial structure was verified by using a confirmatory factor analysis with structural equation modeling.

Results: Of 2203 employees, 362 reported experiencing TRS (16.4\%). Structural equation modeling generated a final model with a goodness of fit index of 0.991 , an adjusted goodness of fit index of 0.984 , and a root mean square error of approximately 0.021 . These indices indicate a strong structural model. The standardized path coefficients for "habitual behavioral factors and TRS," "psychosocial factors and habitual behavioral factors," "psychosocial factors and TRS," and "gender and habitual behavior factors" were $0.48,0.38,0.14$, and 0.18 , respectively.
\end{abstract}

Conclusions: Habitual behavioral factors exert a stronger effect on TRS than do psychosocial factors.

Keywords: Temporomandibular disorders, habitual behavior, psychosocial factors, questionnaire, screening, structural equation modeling,

\section{INTRODUCTION}

Temporomandibular disorders (TMD) include a number of clinical conditions that involve the temporomandibular joint (TMJ), the masticatory muscles, or both [1]. It has been reported that $5-12 \%$ of the general population has TMD [2, 3]. Since the 1970s, a multifactorial etiology for TMD has been proposed, in which pain and dysfunction result from bio-psychosocial factors $[4,5]$. These etiological contributing factors include structural conditions, psychological morbidity, and behavioral problems such as parafunctional habits [6-9].

According to the multifactorial etiology theory, individual factors should be managed at the same time as pathological conditions. However, this approach is sometimes difficult, because each factor may not always be present in all patients. A universal cause of TMD has not been clearly identified to date, further complicating management.

*Address correspondence to this author at the 1-5-45, Yushima, Bunkyo-ku, Tokyo 113-8549, Japan; Tel: +81-3-5803-5713; Fax: +81-3-5803-5713;

E-mail address: anishi.tmj@tmd.ac.jp
It is thought that trauma or habitual behaviors that burden the TMJ and the masticatory muscles influence the development of TMD. Several studies support an association between bruxism and myofacial pain or TMD [10-12]. Molina et al. [13] observed a positive association between bruxism and TMD in a clinically based case control study. Michelotti et al. [14] reported that the habit of maintaining teeth in contact was a significant risk factor for myofacial pain. Furthermore, Kanehira et al. [15] showed that stress is significantly correlated with parafunctions such as sleep bruxism (SB) and daytime clenching.

Relationships between TMD and psychosocial factors such as stress have also been reported. Many studies suggest that psychosocial factors, including depression, stress, and anxiety, play a role in the predisposition, initiation, and progression of TMD and in the responses of TMD patients to treatment [16-20]. It has also been reported that TMD patients who are more anxious are at greater risk of developing chronic pain than those that are less anxious [21].

Sugisaki et al. [22] reported that the prevalence of TMDrelated symptoms (TRS) was higher (approximately 17$18 \%$ ) among the working population than among the general 
Table 1. Questionnaire

\begin{tabular}{|c|l|c|}
\hline \multicolumn{1}{|c|}{ Question Items } & Abbreviated Form \\
\hline \hline Q1 & If you open your mouth wide, can you fit 3 fingers held vertically in your mouth? & Limited mouth opening \\
\hline Q2 & Do you experience pain in the face, jaw, temple, or in the front of the ear when you open and close your mouth? & Mouth-opening pain \\
\hline Q3 & Can you open your mouth without any deviation? & Mouth-opening deviation \\
\hline Q4 & $\begin{array}{l}\text { Do you experience pain in the face, jaw, temple, or in the front of the ear when you eat hard foods such as beef } \\
\text { jerky, dried cuttlefish, or octopus? }\end{array}$ & Chewing-induced pain \\
\hline Q5 & Do you experience stress at work, school, home, or in relationships? & Stress level \\
\hline Q6 & Do you experience anxiety at work, school, home, or in relationships? & Feeling of anxiety \\
\hline Q7 & Do you feel depressed now? & Depressed mood \\
\hline Q8 & Do you feel fatigued even after obtaining rest through sleeping? & Chronic fatigue \\
\hline Q9 & Do you often allow your upper- and lower teeth to make continuous contact during work or at rest? & TCH* \\
\hline Q10 & Do you experience orofacial jaw muscle fatigue or pain when you are awake? & Morning symptoms \\
\hline
\end{tabular}

All the questions were evaluated using a 5-grade rating scale: 1) strongly agree, 2) weakly agree, 3) neither agree nor disagree, 4) weakly disagree, 5) strongly disagree. TCH: tooth contacting habit.

population (5-12\%). They concluded that this difference was attributable to psychological aggravation resulting from duties in the workplace, changes in the work environment, interpersonal relations, and an achievement-oriented climate (e.g., an environment without an employment agreement or one with insufficient output or results).

The Japan Institute for Labour Policy and Training reported that in business establishments, approximately $60 \%$ of employees face a mental health problem, and that the number of affected employees had increased by $30 \%$ over the past 3 years [23].

While some contributing factors influence TMD symptoms directly, other factors may influence them indirectly. To clarify the relationships between TRS and these contributing factors in a working population, we investigated the prevalence of TRS, the contributing factors that affect TRS, and the interactions between those contributing factors.

\section{METHODOLOGY}

This cross-sectional study was performed using an anonymous questionnaire with the approval (No. 325) of the ethics committee of the Tokyo Medical and Dental University, Japan.

\section{Subjects}

We recruited 2723 employees of a particular company that had medical checkups at their work-place during the study period (April to October 2008). The company develops, manufactures, and sells electronic parts. The company's main office and factory are in Tokyo, and it has factories in nearby prefectures. An explanation of the purpose and contents of the study questionnaire was posted at worksites before the study began.

Questionnaires were distributed to all employees along with notification of a medical checkup, and completed questionnaires were collected during the checkup. Of these subjects, 2423 (89\%) completed the questionnaire. Written informed consent was not obtained because identification of individuals was not required; answering the questionnaire was considered consent to participate.

\section{Questionnaire}

The questionnaire administered is shown in Table $\mathbf{1}$. Gender, age, and responses to items 1-10 were recorded.

Items 1-4, which screened patients for TRS, were developed by Sugisaki et al. [24]. The subjects rated the 4 screening items by using a 5 -point numeric rating scale. Sugisaki et al. extracted these 4 items from a 20 -item questionnaire administered to dental patients. The sensitivity, specificity, and false-positive rate derived from TRS screening were 0.746 , 0.811 , and 0.189 , respectively. The total score from those 4 items was used for TRS screening with a cut-off value of 8.5: participants with a score of $\geq 9.0$ were assigned to the TRS group, whereas those with a score of $\leq 8.0$ were assigned to the non-TRS group. One item related to joint noise was omitted from the screening questionnaire, as analysis using nonparametric item response theory (Mokken analysis) showed that the validity of the 4 included items was higher than that of the 5 items.

Items 5-8 assessed psychosocial factors, including stress, anxiety, depressed mood, and chronic fatigue, as described by Sugisaki et al., [22]. Validity of those items was not tested. Items 9 and 10 were related to habitual behavior, including tooth-contacting habit (TCH), in which the upper and lower teeth are continuously brought together with minimal force in a nonfunctional context [25], and morning symptoms that presumably result from SB [26-28]. Subjects used the same 5-point numeric rating scale on all 10 items.

\section{Statistical Analysis}

The questionnaires returned by 220 respondents were incomplete, and thus excluded from the statistical analysis. Data from the remaining 2203 participants (90.9\%) were used for analysis.

Student's $t$-tests and chi-square tests were used to compare age, gender, and prevalence of TRS between the 2 groups. 
Table 2. Characteristics of Subjects

\begin{tabular}{|c|c|c|c|c|}
\hline & Total & non-TRS & TRS & P-value \\
\hline \hline Number (\%) & $2203(100.0)$ & $1841(83.6)$ & $362(16.4)$ & $69(19.1)$ \\
\hline Women (\%) & $314(14.3)$ & $245(13.3)$ & $40.1(8.7)$ & $0.005^{\mathrm{a}}$ \\
\hline Mean age (SD) & $41.2(9.6)$ & $41.4(9.8)$ & $0.018^{\mathrm{b}}$ \\
\hline
\end{tabular}

TRS: TMD-related symptoms; ${ }^{a}$ chi-square test; ${ }^{b}$-test

The cut-off value of the total score for TRS screening (question items $1-4$ ) was 8.5 ; participants with a score of $\geq 9.0$ were assigned to the TRS group, while those scoring $\leq 8.0$ were assigned to the non-TRS group.

Table 3. Correlations of Questionnaire Items with TMD-Related Symptoms

\begin{tabular}{|c|c|c|}
\hline Questionnaire Items & Pearson's Correlation Coefficient $(\boldsymbol{r})$ & $\boldsymbol{P}$-Value \\
\hline \hline Stress level & 0.128 & $<0.001$ \\
\hline Feeling of anxiety & 0.169 & $<0.001$ \\
\hline Depressed mood & 0.165 & $<0.001$ \\
\hline Chronic fatigue & 0.178 & $<0.001$ \\
\hline TCH & 0.107 & $<0.001$ \\
\hline Morning symptoms & 0.261 & $<001$ \\
\hline
\end{tabular}

TCH: tooth contacting habit

Factors influencing TRS (non-TRS, 0; TRS, 1) were estimated using logistic regression analyses with odds ratio (ORs) and 95\% confidence intervals (CI) as measures of association.

Pearson's correlation coefficient between TRS and factors assessed in questionnaire items 5-10 were analyzed to determine covariates. For each item, participants with a score of $\leq 3$ were assigned a value of " 0 ," whereas those with a score of $\geq 4$ were assigned a value of " 1 ." Those items were used as covariates and adjusted for age (1-year increments) and gender (man, 0 ; woman, 1). The covariates were entered into the logistic regression analysis using a stepwise forward technique. $P<0.05$ was considered statistically significant.

The structural equation modeling analysis consisted of 2 phases. First, all variables of a descriptor were divided into parts by exploratory factor analysis (EFA). Second, this factorial structure was verified by confirmatory factor analysis (CFA) with structural equation modeling (SEM). EFA was conducted using SPSS (Version 12, SPSS Japan) and CFA was conducted using AMOS (Version 5.0, SPSS Japan). For both phases of these analyses, the 2203 subjects were randomly divided into 2 groups (designated groups " $\mathrm{C}$ " and "E”) using an algorithm available in SPSS.

Exploratory factor analysis (EFA) was used to define a separate factorial structure. As an initial step, we attempted to minimize the 10 items. Principal factor analysis (promax solution) was employed as an exploratory factor analysis method, to determine the item groups for the questionnaire using the E-group. As a second step, the hypothesized structural model was generated based on this analysis.

Using data from the C-group, confirmatory factor analysis (CFA) was performed, to verify the hypothesized structural models using SEM.

SEM, which is also known as analysis of covariance structures, or causal modeling, is a statistical technique used for testing and estimating causal relationships using a combination of statistical data and qualitative causal assumptions. SEM includes model fitting, testing, and equating, based on the analysis of covariance structures within the framework of a confirmatory data analytical model, and seeks to test data against a hypothesized or theoretical model [29-31]. Because no single index adequately assessed the fit during SEM, we included 3 indices for goodness-of-fit to evaluate the model: the goodness of fit index (GFI), the adjusted goodness of fit index (AGFI), and the root mean square error of approximation (RMSEA). The model was deemed to be well fit when the GFI and AGFI were $>0.90$ and the RMSEA was $<0.05$. Furthermore, standardized path coefficients were considered statistically significant when the critical ratio was $>1.96(P<0.05)$.

Where the goodness-of-fit statistics did not reach a satisfactory level, we modified the model according to the modification indices available in the AMOS program.

\section{RESULTS}

The characteristics of the subject group are shown in Table 2. Of the 2203 employees, 362 were found to have TRS (TRS group, 16.4\%). Women composed a significantly larger proportion of the TRS group than the non-TRS group $(P=0.005)$, and the mean age of the TRS group was significantly lower than that of the non-TRS group $(P=0.018)$.

\section{Logistic Regression Analysis}

Correlation coefficients between TRS and items 5-10 are shown in Table 3. As all correlation coefficients were significant, we used all questions as covariates for logistic regression analyses

The results of the logistic regression analyses are shown in Table 4. Only statistically significant independent variables are shown $(P<0.05)$. Depressed mood (OR, 1.47; 95\% CI, 1.01-2.13), chronic fatigue (OR, 1.96; 95\% CI, 1.10 
Table 4. Logistic Regression Analysis

\begin{tabular}{|c|c|c|c|}
\hline & OR & $\mathbf{9 5 \%}$ CI & P-value \\
\hline \hline $\begin{array}{c}\text { Depressed mood score 1-3 } \\
\text { score 4.5 }\end{array}$ & 1 & $1.01-2.13$ & 0.043 \\
\hline $\begin{array}{c}\text { Chronic fatigue score 1-3 } \\
\text { score 4.5 }\end{array}$ & 1.97 & $1.10-3.51$ & 0.023 \\
\hline $\begin{array}{c}\text { TCH score 1-3 } \\
\text { score 4.5 }\end{array}$ & 1.91 & $1.23-2.95$ & 0.004 \\
Morning symptoms score 1-3 \\
score 4.5
\end{tabular}

OR: odds ratio, CI: confidence interval, TCH: tooth contacting habit

Table 5. Characteristics of Subjects in the E-Group and the C-Group

\begin{tabular}{|c|c|c|c|}
\hline & E-group & C-group & P-value \\
\hline \hline Total & 1102 & 1101 & $0.300^{\mathrm{a}}$ \\
\hline Female (\%) & $166(15.1)$ & $148(13.4)$ & $0.447^{\mathrm{b}}$ \\
\hline Mean age (SD) & $41.1(9.6)$ & $41.4(9.7)$ & $0.646^{\mathrm{a}}$ \\
\hline TMD (\%) & $177(16.1)$ & $185(16.8)$ & \\
\hline
\end{tabular}

${ }^{a}$ chi-square test

${ }^{\mathrm{b}}$ t-test.

Table 6. Questionnaire Items and Factor Loading of Factor Analysis on the E-group

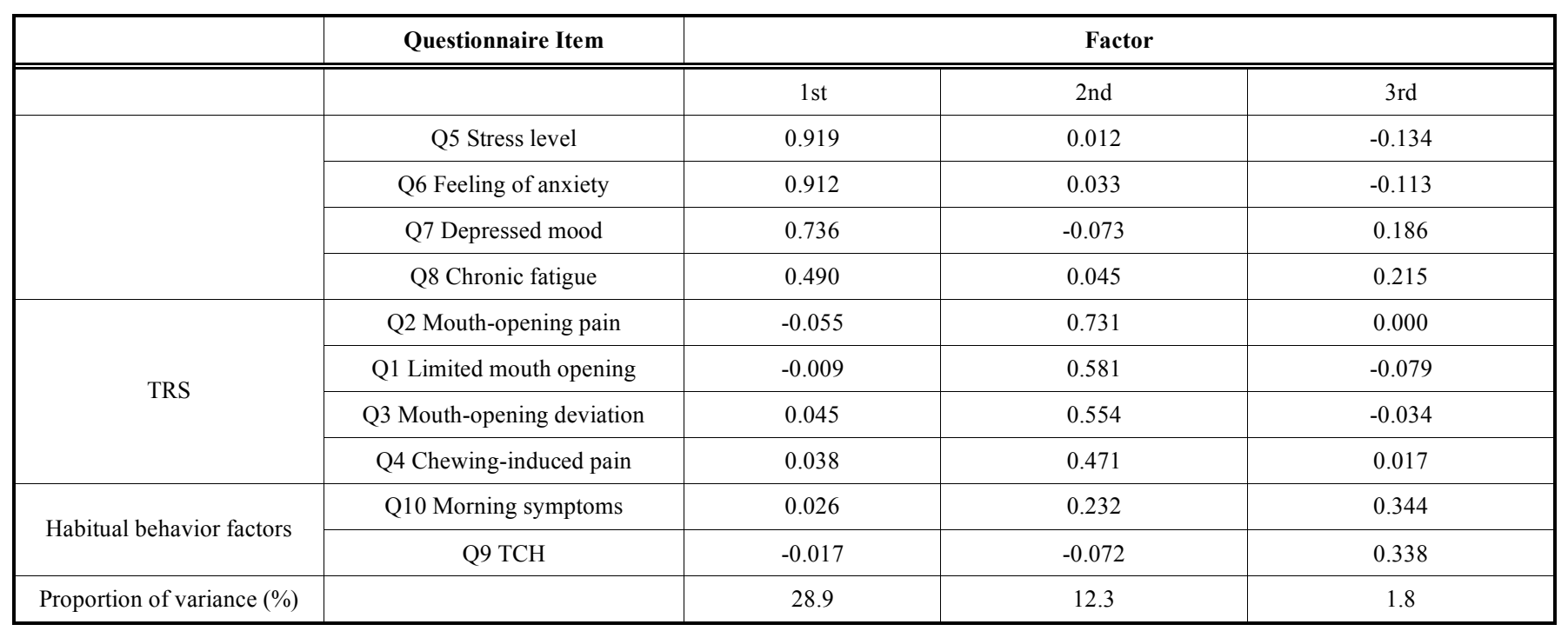

TRS: TMD-related symptoms, TCH: tooth contacting habit

Based on the results, we identified three latent variables; (1) Psychological factor, (2) Symptoms of TMD, and (3) Habitual behavioral factors.

3.51), TCH (OR, 1.91; 95\% CI, 1.23-2.95), and morning symptoms (OR, 2.78; 95\% CI, 2.19-3.52) were found to be significant factors contributing to the manifestation of TRS.

\section{Exploratory Factor Analysis}

Characteristics of the C-group and E-group are shown in Table 5. There were no significant differences between these groups with respect to age, or the prevalence of TRS.

As a result of factor analysis of the E-group, 3 factors were extracted (Table 6). It was assumed that items 5-8 comprised the first factor, items 1-4 comprised the second factor, and items 9 and 10 the third factor. We named the first, second, and third factors as "psychosocial factors,"
"TRS," and "habitual behavioral factors," respectively. A hypothesized structural model including the observed variables was generated from these results (Fig. 1).

\section{Confirmatory Factor Analysis}

We performed confirmatory factor analysis using SEM to investigate the hypothesized structural model. Significant standardized path coefficients in the final model are shown in Fig. (2). The fit indices of the final model were as follows: $\mathrm{GFI}=0.991, \mathrm{AGFI}=0.984$, and $\mathrm{RMSEA}=0.021$. These indices indicated a strong structural model.

The standardized path coefficients for "habitual behavioral factors and TRS," "psychosocial factors and habitual 


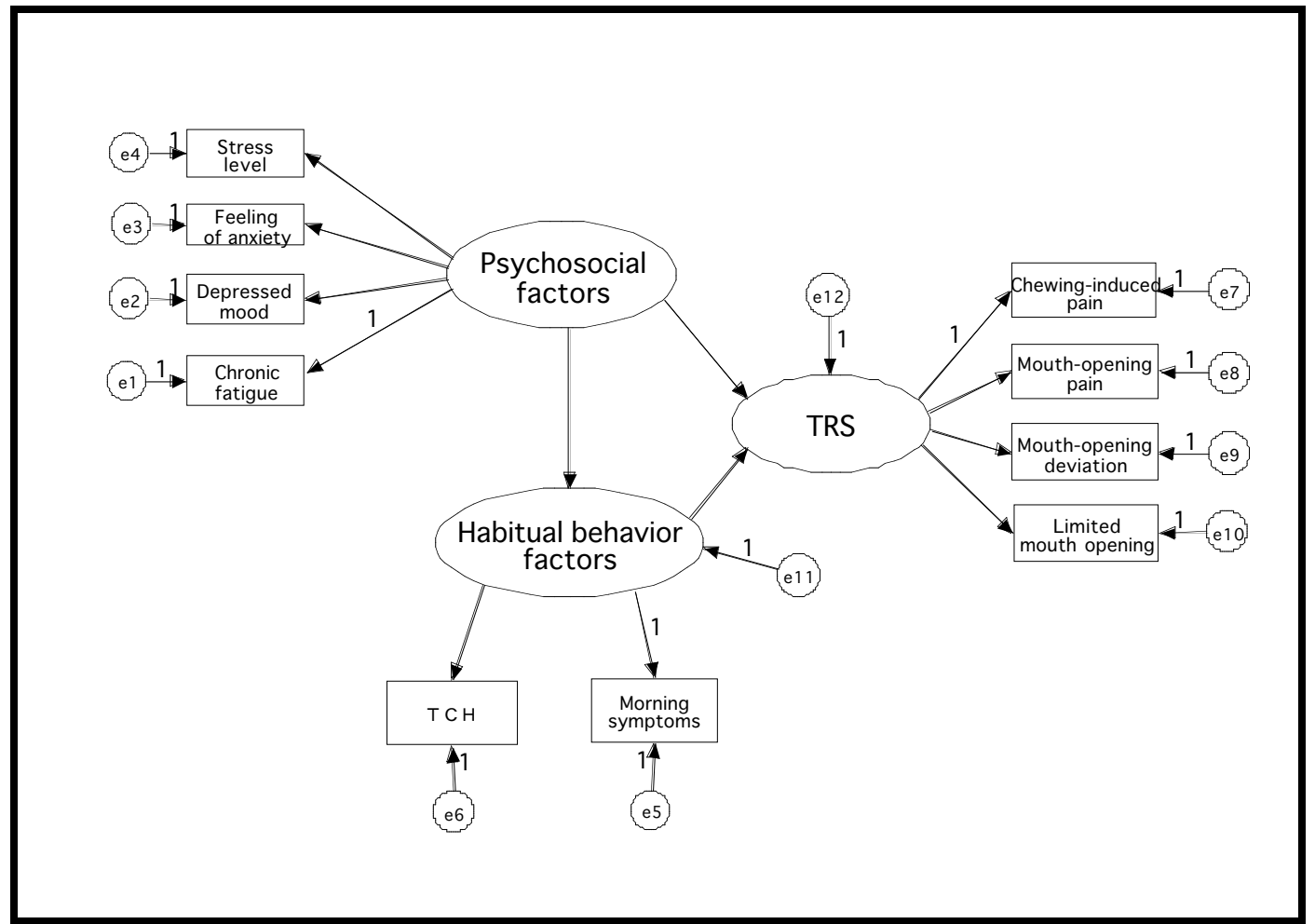

Fig. (1). Hypothesized structural model including observed variable e1 to e12 are error variables. TRS: TMD-related symptoms, TCH: tooth contacting habit.

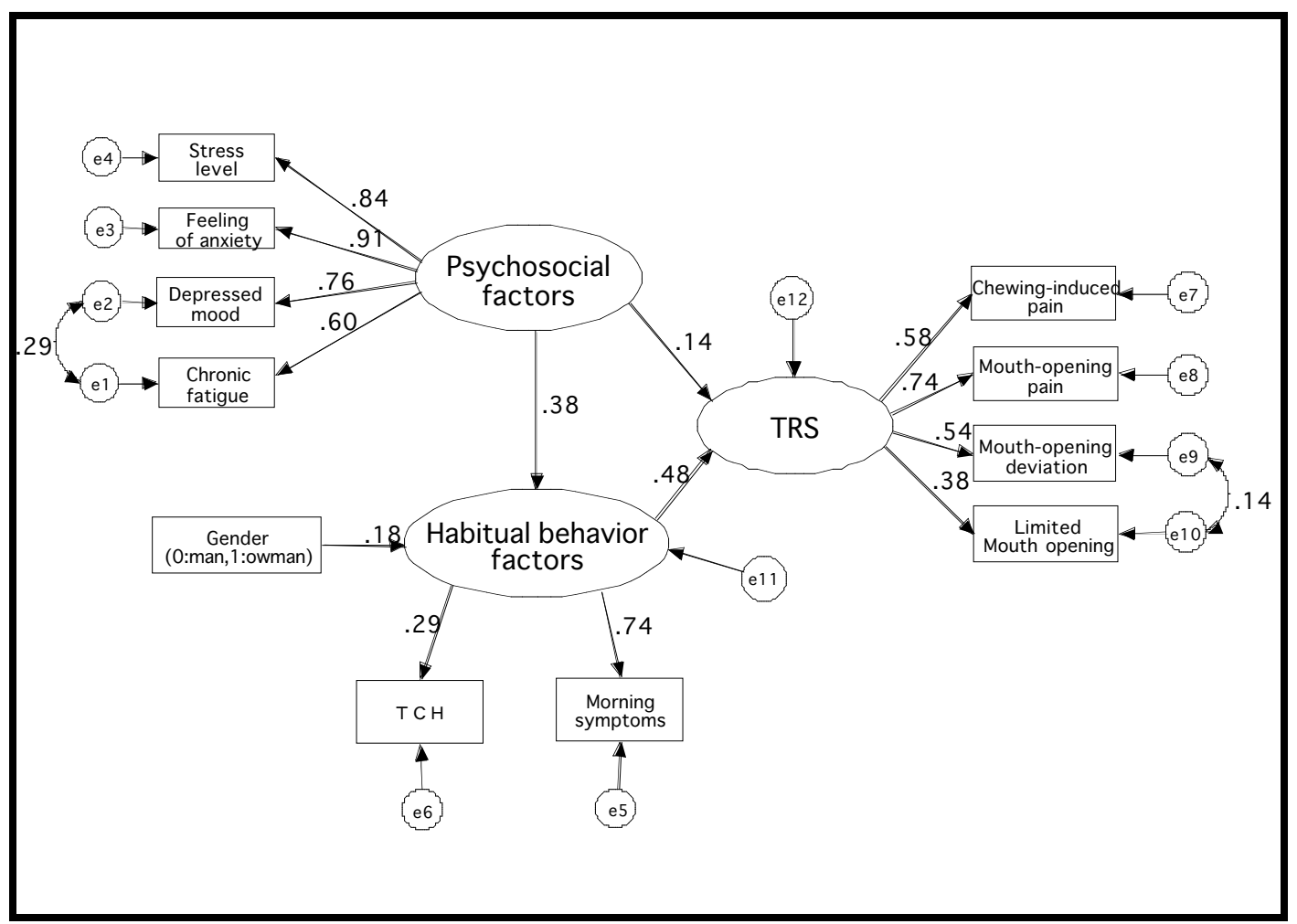

Fig. (2). Standardized path coefficients GFI $=0.991$, AGFI $=0.984$, RMSEA $=0.021$; e1 to e12 are error variables. TRS: TMD-related symptoms, TCH: tooth contacting habit.

behavioral factors," "psychosocial factors and TRS," and "gender and habitual behavior factors" were $0.48,0.38,0.14$, and 0.18 , respectively. These standardized path coefficients were statistically significant (Table 7).

\section{DISCUSSION}

Women formed a significantly larger proportion of the TRS group (19.1\%) than the non-TRS group (13.3\%). It has 
Table 7. Critical Ratio and $P$-Value in Standardized Path Coefficients

\begin{tabular}{|ccc|c|c|}
\hline & & & Critical Ratio & P-Value \\
\hline \hline Habitual behavior factors & $\Rightarrow$ & TRS & 4.187 & $<0.001$ \\
\hline Psychosocial factors & $\Rightarrow$ & TRS & 2.190 & 0.029 \\
\hline Psychosocial factors & $\Rightarrow$ & Habitual behavior factors & 8.856 & $<0.001$ \\
\hline Gender & $\Rightarrow$ & Habitual behavior factors & 4.819 & $<0.001$ \\
\hline
\end{tabular}

TRS: TMD-related symptoms.

Standardized path coefficients are significant statistically when the critical ratio is greater or equal to 1.96

been reported that patients requiring treatment for TMD are predominantly women [32]. Thus, our data confirm the widely reported relationship between gender and painful TMD symptoms [33-35].

Depressed mood, chronic fatigue, $\mathrm{TCH}$, and morning symptoms were found by logistic regression analyses to be significant factors contributing to TRS. Manfredini et al. [36] reported that pain-related disability was strongly correlated with depression and somatization levels in a multicenter questionnaire study. Korszun et al. [37] showed that $42 \%$ of a group of patients with chronic fatigue syndrome or fibromyalgia reported temporomandibular disorders. In our study, ORs of depressed mood and chronic fatigue were 1.47 and 1.96 , respectively. This suggests that when both factors are prevalent, the risk of TRS is increased $(\mathrm{OR}=2.88)$.

Several studies support an association between bruxism and myofacial pain or TMD [12-14]. It is possible that SB causes TMJ pain and/or jaw muscle pain in the morning [38] and that morning symptoms represent an important element in diagnosing SB when a patient seeks advice relating to tooth grinding or clenching [26]. Dubé et al. [39] also used morning orofacial jaw muscle fatigue to diagnose SB. It has been shown that mandibular condyle is displaced and TMJ stress is increased by the occlusal force [40-43]. Baba et al. [44] reported that the frequency of clicking increased with the severity of subjectively evaluated SB.

In 2006, Sato et al. [25] first described daytime light clenching TCH. TCH was defined as a habitual behavior in which the upper and lower teeth are continuously brought together with minimal force in a non-functional situation, i.e., contact but not clenching. We considered TCH a risk factor for TMD, since the activity of the masticatory muscles in the intercuspal position was shown to be higher than when at rest [45]. Using a radio wave-activated wrist vibrator, Chen et al. [46] showed that patients with myogenous pain exhibit nearly 4 times more non-functional tooth contact during the daytime than healthy controls. Michelotti et al. [16] also reported that the habit of maintaining tooth contact was a significant risk factor for myofacial pain. Given that the average total time of functional tooth contact during chewing or swallowing is only $17.5 \mathrm{~min} /$ day [47], it is thought that continuous non-functional tooth contact causes overload of the TMJ and the masticatory muscles. In fact, it has been shown that the association between clenching and muscle pain is either due to damaged muscle fibers or to a reduction in blood supply to these fibers, as the perfusion of the masseter was significantly lowered [40, 48-52] during clenching. Therefore, TCH also affected the onset, persistence, and aggravation of TMD [22, 25].

Our SEM analysis showed that gender influenced habitual behavior factors and suggested an association between TRS, psychosocial factors, and habitual behavior factors.

Habitual behavior influenced TRS directly, whereas psychosocial factors influenced habitual behavior but did not directly influence TRS. This shows that added force on the TMJ and masticatory muscles has a direct influence on TMD.

Psychosocial factors such as anxiety and depressed mood act as secondary factors that can elevate habitual behaviors such as SB and TCH. Pingitore et al. [53] found that the total score of life stress events was significantly and positively correlated with bruxism in 125 dental patients. Kanehira et al. [15] reported that stress was significantly correlated with parafunctions such as SB and daytime clenching. Furthermore, Manfredini et al. [54] showed that wake-time clenching appears to be associated with psychosocial factors. Regarding the difference between men and women, SB is reportedly weakly associated with some aspects of job stress in the male but not in female the Japanese working population [55]. In this study, because the standardized path coefficient from psychosocial factors to habitual behavioral factors was significant, we suggest that psychosocial factors are associated with SB and TCH. According to our previous study of the same workforce, TRS was associated with an increase in both anxiety and habitual behaviors, similar to the way that morning symptoms are associated with SB and TCH [22].

Various factors such as working hours, and working environment, influence psychosocial factors. We assessed visual display terminal (VDT) work in the working environment because several reports suggest that VDT use influences musculoskeletal symptoms. VDTs are now used in many workplace situations, and the number of individuals exposed to these systems has consequently increased in recent years. Nakazawa et al. [56] reported that the likelihood of developing physical symptoms such as headache, neck pain, back pain, and eye strain increased when daily exposure to VDTs exceeded $3 \mathrm{~h}$, and that mental and sleep disorders could be prevented by restricting the use of VDTs to $\leq 5$ $\mathrm{h} /$ day. In addition, prolonged and uninterrupted daily VDT usage causes eye strain and musculoskeletal pain, both of which are associated with deterioration of mental health [57, 58]. Because TMD is considered a symptom of the musculoskeletal system, it is conceivable that VDT use has an indirect influence on TMD. 
These observations indicate that correction of habitual behaviors is important for the treatment of TMD, because those factors influence TRS directly. However, it is difficult to control SB because its cause is unknown. Therefore, we suggest that the control of $\mathrm{TCH}$ is an important goal in the effective treatment of TMD.

We advocate the use of behavior modification to control $\mathrm{TCH}$. Behavior modification is the use of empirically demonstrated techniques to improve behavior. Behavior modification targets behaviors that can be objectively measured and aims to control these behaviors by reinforcing adaptive behavior and/or reducing maladaptive behavior. This process consists of behavioral assessment to measure the target behavior and subsequent modification to change that behavior. We propose that $\mathrm{TCH}$ can be effectively controlled using a time sampling method for behavioral assessment and the habit reversal method for modification. These procedures consist of 3 steps. The first step is "motivation strategy," in which the patient confirms habitual behavior using reminders such as tags, stickers, and timers. The second step entails "awareness training" and "competing response training," in which the patient performs a substitute action in place of the adverse habitual behavior (for example, taking a deep breath) just after becoming aware of it, via a reminder. After performing the behavior modification procedures, the patient will feel less jaw muscle strain. The final step is "reinforcement," in which the patient increases the frequency of noticing the behavior by performing the first and second steps repeatedly.

Our results indicate that habitual behaviors such as SB and $\mathrm{TCH}$ are contributing factors that directly influence TRS, whereas psychosocial factors such as stress, anxiety, and depressive mood are secondary factors that elevate habitual behaviors. In the future, it will be necessary to consider habitual behavior factors other than $\mathrm{SB}$ and $\mathrm{TCH}$. In addition, factors that influence TRS and aspects of the work environment that lead to psychosocial deterioration should be examined separately.

The subjects in the current study may not be entirely representative of the general population, as they were all employees of single company. Future investigations involving employees from various type of industry, of the general population, will be of further interest.

\section{CONCLUSIONS}

The relationship between TRS and contributing factors such as psychosocial and habitual behaviors was reviewed using SEM in a working population. We showed that habitual behavioral factors such as stress, anxiety, depression, and fatigue, had a stronger effect on TRS than psychosocial factors such as SB and TCH. Further, psychosocial factors lead to the development of habitual behaviors, and these habitual behaviors lead to the development of TRS. Future studies should consider other factors such as occlusion, and additional habitual behaviors and work environments.

\section{CONFLICTS OF INTEREST}

The authors declare no conflicts of interest.

\section{ACKNOWLEDGEMENTS}

We thank the subjects who participated in this study.

\section{REFERENCES}

[1] Okeson JP. Orofacial pain: Guidelines for assessment, diagnosis and management. Chicago: Quintessence 1996.

[2] Rough JD, Solberg WK. Oral health status in the United States: temporomandibular disorders. J Dent Educ 1985; 49: 398-406.

[3] Dworkin SF, Huggins KH, LeResche L, et al. Epidemiology of signs and symptoms in temporomandibular disorders: clinical signs in cases and controls. J Am Dent Assoc 1990; 120: 273-81.

[4] Weinberg LA. Temporomandibular dysfunctional profile: a patientoriented approach. J Prosthet Dent 1974; 32: 312-25.

[5] Oral K, Bal Küçük B, Ebeoğlu B, et al. Etiology of temporomandibular disorder pain. Agri 2009; 21: 89-94.

[6] Moss RA, Garrett JC. Temporomandibular joint dysfunction syndrome and myofacial pain dysfunction syndrome: a critical review. J Oral Rehabil 1984; 11: 3-28.

[7] Schiffman EL, Fricton JR, Haley D. The relationship of occlusion, parafunctional habits and recent life events to mandibular dysfunction in a non-patient population. J Oral Rehabil 1992; 19: 201-23.

[8] Laskin DM. Etiology of the pain-dysfunction syndrome. J Am Dent Assoc 1969; 79: 147-53.

[9] Yap AU, Dworkin SF, Chua EK, et al. Prevalence of temporomandibular disorders subtypes, psychologic distress, and psychosocial dysfunction in Asian patients. J Orofac Pain 2003; 17: 21-8.

[10] Dahlstrom JR, Carlsson SG, Gale EEN, et al. Stress-induced muscular activity in mandibular dysfunction: effects of biofeedback training. J Behav Med 1985; 8: 191-200.

[11] Glaros AG, Glass EG, Brockman D. Electromyographic data from TMD patients with myofacial pain and from matched control subjects: evidence for statistical, not clinical, significance. J Orofac Pain 1997; 11: 125-9.

[12] Mercuri LG, Olson RE, Laskin DM. The specificity of response to experimental stress in patients with myofacial pain dysfunction syndrome. J Dent Res 1979; 58: 1866-71.

[13] Molina OF, dos Santos Jr J, Nelson SJ, et al. Prevalence of modalities of headaches and bruxism among patients with craniomandibular disorder. Cranio 1997; 15: 314-25.

[14] Michelotti A, Cioffi I, Festa P, et al. Oral parafunctions as risk factors for diagnostic TMD subgroups. J Oral Rehabil 2010; 37: 157-62.

[15] Kanehira H, Agariguchi A, Kato H, et al. Association between stress and temporomandibular disorder. Nihon Hotetsu Shika Gakkai Zasshi 2008; 52: 375-80.

[16] Sipilä K, Veijola J, Jokelainen J, et al. Association between symptoms of temporomandibular disorders and depression: an epidemiological study of the Northern Finland 1966 Birth Cohort. Cranio 2001; 19: 183-7.

[17] Auerbach SM, Laskin DM, Frantsve LM, et al. Depression, pain, exposure to stressful life events, and long-term outcomes in temporomandibular disorder patients. J Oral Maxillofac Surg 2001; 59: 628-33.

[18] Rollman GB, Gillespie JM. The role of psychosocial factors in temporomandibular disorders. Curr Rev Pain 2000; 4: 71-81.

[19] Ahlberg J, Nikkila H, Kononen M, et al. Associations of perceived pain and painless TMD-related symptoms with alexithymia and depressive mood in media personnel with or without irregular shift work. Acta Odontol Scand 2004; 62: 119-23.

[20] Nishiyama A, Kino K, Sugisaki M, et al. Examination of the contributing factor associated with temporomandibular disorders in working population (in Japanese). J Jpn Soc TMJ 2010; 22: 1-9.

[21] Wright AR, Gatchel RJ, Wildenstein L, et al. 3rd. Biopsychosocial differences between high-risk and low-risk patients with acute TMD-related pain. J Am Dent Assoc 2004; 135: 474-83.

[22] Sugisaki M, Takano N, Kino K, et al. Prevalence of temporomandibular disorders among working population of Tokyo (in Japanese). J Jpn Soc TMJ 2008; 20: 127-33.

[23] Investigation about measures to mental health care at workplace in 2003. The Japan Institute for Labor Policy and Training : Available from: http://www.jil.go.jp/ 
[24] Sugisaki M, Kuruma R, Kino K, et al. Selection of question items for screening patients with temporomandibular disorders and estimation of their validity. J Jpn Soc TMJ 2007; 19: 177-84 (in Japanese).

[25] Sato F, Kino K, Sugisaki M, et al. Teeth contacting habit as a contributing factor to chronic pain in patients with temporomandibular disorders. J Med Dent Sci 2006; 53: 103-9.

[26] Bader G, Lavigne G. Sleep bruxism; an overview of an oromandibular sleep movement disorder. Sleep Med Rev 2000; 4: 27-43.

[27] Dubé C, Rompré PH, Manzini C, et al. Quantitative polygraphic controlled study on efficacy and safety of oral splint devices in tooth-grinding subjects. J Dent Res 2004; 83: 398-403.

[28] Rompre PH, Daigle-Landry D, Guitard F, et al. Identification of a sleep bruxism subgroup with a higher risk of pain. J Dent Res 2007; 86: 837-42

[29] Bock RD, Bargmann R. Analysis of covariance structures. Psychometrika 1966; 31: 507-34.

[30] Muthen B. A general structural equation model with dichotomous, ordered categorical, and continuous latent variable indicators. Psychometrika 1984; 49: 115-32.

[31] Arbuckel JL. Amos 4.0 user's guide. Chicago: SmallWaters, 1999.

[32] McNeill C. The optimum temporomandibular joint condyle position in clinical practice. Int J Periodont Restorative Dent 1985; 5: 52-76.

[33] Cimino R, Farella M, Michelotti A, et al. Does the ovarian cycle influence the pressure-pain threshold of the masticatory muscles in symptom-free women? J Orofac Pain 2000; 14: 105-11.

[34] Dao TT, LeResche L. Gender differences in pain. J Orofac Pain 2000; 14: 169-84.

[35] LeResche L, Mancl LA, Drangsholt MT, et al. Predictors of onset of facial pain and temporomandibular disorders in early adolescence. Pain 2007; 129: 269-78.

[36] Manfredini D, Winocur E, Ahlberg J, et al. Psychosocial impairment in temporomandibular disorders patients. RDC/TMD axis II findings from a multicentre study. J Dent 2010; 38: 765-72.

[37] Korszun A, Papadopoulos E, Demitrack M, et al. The relationship between temporomandibular disorders and stress-associated syndromes. Oral Surg Oral Med Oral Pathol Oral Radiol Endod 1998; 86: 416-20.

[38] Lavigne GJ, Rompre PH, Montplaisir JY. Sleep bruxism: validity of clinical research diagnostic criteria in a controlled polysomnographic study. J Dent Res 1996; 75: 546-52.

[39] Dubé C, Rompré PH, Manzini C, et al. Quantitative polygraphic controlled study on efficacy and safety of oral splint devices in tooth-grinding subjects. J Dent Res 2004; 83; 398-403.

[40] Buzinelli RV, Berzin F. Electromyographic analysis of fatigue in temporalis and masseter muscles during continuous chewing. $\mathrm{J}$ Oral Rehabil 2001; 28: 1165-7.

[41] Yamazaki M, Yugami K, Baba K, et al. Effect of clenching level on mandibular displacement in Kennedy Class II partially edentulous patients. Int J Prosthodont 2003; 16: 183-8.
[42] Hirose M, Tanaka E, Tanaka M, et al. Three-dimensional finiteelement model of the human temporomandibular joint disc during prolonged clenching. Eur J Oral Sci 2006; 114: 441-8.

[43] Nishio C, Tanimoto K, Hirose M, et al. Stress analysis in the mandibular condyle during prolonged clenching: a theoretical approach with the finite element method. Proc Inst Mech Eng H 2009; 223: 739-48.

[44] Baba K, Haketa T, Sasaki Y, et al. Association between masseter muscle activity levels recorded during sleep and signs and symptoms of temporomandibular disorders in healthy young adults. $\mathrm{J}$ Orofac Pain 2005; 19: 226-31.

[45] Michelotti A, Farella M, Vollaro S, et al. Mandibular rest position and electrical activity of the masticatory muscles. J Prosthet Dent 1997; 78: 48-53.

[46] Chen CY, Palla S, Erni S, et al. Nonfunctional tooth contact in healthy controls and patients with myogenous facial pain. J Orofac Pain 2007; 21: 185-92.

[47] Graf H. Bruxism. Dent Clin North Am 1969; 13: 659-65.

[48] Svensson P, Burgaard A, Schlosser S. Fatigue and pain in human jaw muscles during a sustained, low-intensity clenching task. Arch Oral Biol 2001; 46: 773-7.

[49] Kim YJ, Kuboki T, Tsukiyama Y, et al. Haemodynamic changes in human masseter and temporalis muscles induced by different levels of isometric contraction. Arch Oral Biol 1999; 44: 641-50.

[50] Larsson SE, Bengtsson A, Bodegard L, et al. Muscle changes in work-related chronic myalgia. Acta Orthop Scand 1988; 59: 552-6.

[51] Larsson B, Bjork J, Kadi F, et al. Blood supply and oxidative metabolism in muscle biopsies of female cleaners with and without myalgia. Clin J Pain 2004; 20: 440-6.

[52] Nakamura $\mathrm{Y}$, Torisu $\mathrm{T}$, Noguchi $\mathrm{K}$, et al. Changes in masseter muscle blood flow during voluntary isometric contraction in humans. J Oral Rehabil 2005; 35: 545-51.

[53] Pingitore G, Chrobak V, Petrie J. The social and psychologic factors of bruxism. J Prosthet Dent 1991; 65: 443-6.

[54] Manfredini D, Lobbezoo F. Role of psychosocial factors in the etiology of bruxism. J Orofac Pain 2009; 23: 153-66.

[55] Nakata A, Takahashi M, Ikeda T, et al. Perceived psychosocial job stress and sleep bruxism among male and female workers. Community Dent Oral Epidemiol 2008; 36: 201-9.

[56] Nakazawa T, Okubo Y, Suwazono Y, et al. Association between duration of daily VDT use and subjective symptoms. Am J Ind Med 2002; 42: 421-6.

[57] Ye Z, Honda S, Abe Y, et al. Influence of work duration or physical symptoms on mental health among Japanese visual display terminal users. Ind Health 2007; 45: 328-33.

[58] Ye Z, Abe Y, Kusno Y, et al. The influence of visual display terminal use on the physical and mental conditions of administrative staff in Japan. J Physiol Anthropol 2007; 26: 69-73.

(C) Nishiyama et al.; Licensee Bentham Open.

This is an open access article licensed under the terms of the Creative Commons Attribution Non-Commercial License (http://creativecommons.org/licenses/by-nc/3.0/) which permits unrestricted, non-commercial use, distribution and reproduction in any medium, provided the work is properly cited. 